\title{
Graves' Orbitopathy: A Multidisciplinary Approach. 2nd revised edition Eds: Wiersinga WM, Kahaly GJ 2010 XVI+286 pp, 95 fig., 53 in color, 41 tab., soft cover ISBN 978-3-8055-9531-5. Karger, Basel
}

\author{
Joachim Esser
}

Received: 22 September 2011 / Accepted: 28 September 2011 /Published online: 29 October 2011

(C) Springer-Verlag 2011

The first edition of Graves' Orbitopathy: A Multidisciplinary Approach was so well-received that after just 3 years a second, revised edition is published. This is partially due to its exceptional question-and-answer format and the comprehensive multidisciplinary approach: Wilmar Wiersinga (Amsterdam) and Georges Kahaly (Mainz) have chosen the right combination of endocrinologists and ophthalmologists who shed light on all aspects of Graves' orbitopathy (GO) from their respective points of view. The coordination of 27 authors to write a companion on a single complex of symptoms is a difficult task at best. They represent the European Group on Graves' Orbitopathy (EUGOGO) which is recruited from 13 clinical centres in eight European countries.

The layout and concept make this book easy to read and useful: In each of the 25 chapters, about 10-20 clinically relevant questions are given (e.g., "What signs are helpful for assessing severity? What is apical crowding? What should you do if steroids fail? Is botulinum toxin useful? "). These questions are promptly answered in a way that makes this book also useful as a clinical manual. Special and difficult cases, such as GO in children or diabetics, are also included. A number of summaries present standardized examination techniques and patient management, according to different grades of severity, and offers recommendations concerning the inclusion of specialists in disease management.

In the 2nd edition, all chapters have been carefully updated especially with regard to pathogenesis and treatment. The EUGOGO consensus recommendations which were published in 2008 in Thyroid and the European Journal of Ophthalmology are fully incorporated in the text. Two new chapters have been added: one describing the socioeconomic impact of GO and the other outlining the Amsterdam declaration on GO. This declaration, aiming to improve outcomes for thyroid eye disease, was signed by 82 national and international organizations in the field of thyroidology and ophthalmology at the International Symposium on GO in Amsterdam 2010.

This newly updated edition is a valuable overview on the cutting edge of management of GO, and a valuable asset for any ophthalmologist or specialist treating patients with Graves`disease.

\footnotetext{
J. Esser $(\square)$

Universitäts-Augenklinik, Abteilung für Erkrankungen der vorderen Augenabschnitte/Orthoptik,

Hufelandstrasse 55,

45122 Essen, Germany

e-mail: joachim.esser@uni-essen.de
} 